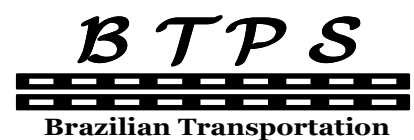

Planning Society
Journal of Transport Literature

Vol. 6, n. 4, pp. 147-163, Oct 2012

Reviews \& Essays
JTL | RELIT

www.transport-literature.org ISSN 2238-1031

\title{
Planejamento aeroportuário no Brasil: discussão sobre contribuições da prospectiva estratégica
}

[airport planning in Brazil: discussions on contributions of strategic prospective]

\author{
George Christian Linhares*
}

Agência Nacional de Aviação Civil (ANAC), Brazil

Submitted 5 May 2011; received in revised form 27 Jan 2012; accepted 30 Jan 2012

\begin{abstract}
Resumo
0 artigo aborda o planejamento aeroportuário enquanto problema de política pública, inserindo-o na perspectiva das relações de poder entre agentes envolvidos ou interessados no processo de planejamento (stakeholders). 0 objetivo é apresentar referências oriundas do campo da prospectiva estratégica que possam ser de interesse para o trato do problema do planejamento aeroportuário no Brasil. Importante elemento da infraestrutura de uma região, decisões sobre o desenvolvimento de um aeroporto são interesse legítimo de diversos atores e, assim, se demonstram adequadas as contribuições da prospectiva estratégica, que considera os interesses dos atores envolvidos na problemática analisada. Fundamentado em revisão bibliográfica e análise do planejamento aeroportuário no contexto brasileiro, o artigo reforça a natureza complexa do planejamento de aeroportos e traz como conclusões a necessidade de analisar os objetivos e interesses das partes interessadas e a defesa do uso de metodologias prospectivas para o ambiente de planejamento nacional indicando espaço para ensaios de aplicação do método MACTOR.
\end{abstract}

Palavras-Chave: planejamento aeroportuário; stakeholders; prospectiva estratégica.

\begin{abstract}
This paper takes up the airpot planning as a public policy problem, placing it in the context of relations between the agents involved or interested in the planning process. The aim is to present references from the field of strategic prospective that can be useful for Brazilian airport planning process. Such an important element of the infrastructure in a region, decisions regarding airport development impact several stakeholders, thus contributions of strategic prospective shown to be appropriate. Based on bibliographic review and analysis of airport planning in Brazilian context, the paper reinforces the complex nature of airport planning and the conclusions support the need to analyse the relantionship between the stakeholders and support the applicability of prospective methods for the context of national airport planning, particularly the MACTOR.
\end{abstract}

Key words: airport planning; stakeholders; strategic prospective.

* Email: geochristian@hotmail.com.

\section{Recommended Citation}

Linhares, G. C. (2012) Planejamento aeroportuário no Brasil: discussão sobre contribuições da prospectiva estratégica. Journal of Transport Literature, vol. 6, n. 4, pp. 147-163.

- JTL/RELIT is a fully electronic, peer-reviewed, open access, international journal focused on emerging transport markets and published by BPTS - Brazilian Transport Planning Society. Website www.transport-literature.org. ISSN 2238-1031. 


\section{Introdução}

Desde o início da década de 1990 o Brasil evidencia um movimento de mudanças no setor de transporte aéreo o qual apresentou alguns resultados benéficos, como a ampliação da oferta de voos e a maior competição por preços entre empresas aéreas.

Associadas às alterações nos marcos legais que disciplinam as atividades do setor, essas mudanças propiciaram uma reestruturação do mercado e, consequentemente, movimentos de ajustamento representado pela falência de algumas empresas aéreas tradicionais e entrada de empresas dentro de uma proposta de operação com custos reduzidos para oferta de tarifas mais competitivas.

Muito embora não se configure um movimento contínuo e explícito no sentido de uma liberalização do setor, e não obstante um recrudescimento da postura intervencionista do Estado em alguns momentos (GUIMARÃES, 2003), pode-se defender que esse movimento acaba por resultar na substituição da estratégia de regulação protetora dos agentes econômicos que vigorou por décadas por uma regulação baseada na figura de uma agência constituída sob princípos de autonomia e independência e, ao nível institucional, justificada para atuar na defesa da livre concorrência e busca pela eficência do setor.

Apesar desse cenário de mudanças, é possível defender que neste período desde 1990 até a atualidade não é evidenciável um padrão diretivo no que toca ao planejamento da infraestrutura aeroportuária para suportar o incremento da demanda. $\mathrm{O}$ crescimento da economia nacional nas décadas de 1990 e 2000 e o aumento da renda média possibilitaram condições favoráveis para a expansão do mercado. No entanto, a ampliação da infraestrutura em termos de capacidade de processamento de aeronaves e passageiros é apontada como insuficiente (PALHARES e ESPÍRITO SANTO JR, 2001; SALGADO, 2009; JESUS JR e FERREIRA JR, 2010).

Considerando que o investimento em infraestrutura aeroportuária envolve altas somas, muitas vezes custos afundados (sunk costs), horizonte de retorno de médio para longo prazo e integração estrita com diversos atores da sociedade. Somando-se a isso as dimensões continentais do país e a diversidade nas práticas de gestão do diversos entes da federação, não 
se pode esperar uma mudança radical no cenário brasileiro sem um efetivo e integrado esforço de planejamento por parte do Estado nacional.

Posto que o governo federal é o responsável pela exploração dos principais aeroportos nacionais através da estatal Empresa Brasileira de Infraestrutura Aeroportuária - INFRAERO, que detém efetivo monopólio no país tendo processado aproximadamente 97\% da movimentação de passageiros no país em 2009 (INFRAERO, 2010), a importância de uma diretriz governamental para o planejamento do setor é ressaltada. No contexto de concessão da infraestrutura aeroportuária o papel do governo é fundamental para a definição de marcos regulatórios capazes de induzir eficiência na alocação de recursos privadas para atendimento do interesse público ao tempo que garantam um retorno adequado para os investimentos.

As discussões sobre o planejamento aeroportuário permeiam diferentes áreas do conhecimento e os enfoques aplicados podem ser os mais diversos. Neste artigo toma-se o tema enquanto problema de política pública e sob a perspectiva dos estudos de estratégia que enfocam as relações de poder entre os agentes envolvidos com o processo de planejamento. Por se tratar o aeroporto de importante elemento da infraestrutura de transporte de uma região, que ocupa extensa aérea e processa atividades que podem impactar diversas partes da sociedade, as decisões sobre os rumos de seu desenvolvimento são objeto de interesse de vários atores.

Intenciona-se neste trabalho especificamente relacionar o problema do planejamento aeroportuário com as contribuições da prospectiva estratégica, que consolida referências teóricas e técnicas mediante as quais se busca chegar a uma compreensão mais completa das forças que moldam o futuro de longo prazo e que devem ser levadas em conta na formulação de políticas, no planejamento e na tomada de decisões (COATES, 1985).

Essa perspectiva ampla para a leitura do ambiente sócio-político onde ocorre e para onde se destinam os resultados da formulação do processo de planejamento se demonstra adequada para lidar com as peculiaridades do planejamento de aeroportos. Assim, o objetivo do artigo é identificar referências conceituais, técnicas, metodologias e outras contribuições oriundas do campo da prospectiva estratégica que possam ser de interesse para o trato do problema do planejamento aeroportuário no âmbito do Brasil. 
A relevância da prospectiva estratégica para subsidiar ações de planejamento de longo prazo, tais como da infraestrutura aeroportuária, repousa sobre suas próprias características, que agregam elementos de uma abordagem sistêmica ao problema e, principalmente, a leitura da interação com os diversos atores da sociedade em busca da identificação e até mesmo tentativa de mensuração de possíveis alianças ou conflitos que podem ser impeditivos ou catalisadores para a consecução dos objetivos do planejamento.

Em termos da estrutura, na próxima seção o artigo contextualiza o problema por meio de uma revisão da literatura sobre os tópicos referenciados, o que segue nas próximas duas seções. Após isso, as considerações do autor são apresentadas com o intuito de fomentar uma reflexão sobre as contribuições do campo da prospectiva estratégica para o planejamento aeroportuário.

\section{Planejamento aeroportuário}

O aeroporto é dos mais importantes elementos da infraestrutura de transporte de uma região e, conforme Ashford et Al. (1997), representa uma parte essencial do sistema de transporte aéreo porque é o local físico onde ocorre a troca do modal terrestre pelo modal aéreo e vice e versa.

Tradicionalmente a infraestrutura aeroportuária é considerada um bem público, cujo conceito traz a idéia de que sua oferta envolve altas somas em investimento para atendimento da coletividade e, portanto, sua exploração pela iniciativa privada só é conveniente quando há elevado ganho de escala e certa proteção contra a competição.

Nessa perspectiva, o fornecimento de um bem público requer sempre atuação estatal, seja através da exploração direta, seja através da definição de regulamentos para disciplinar a exploração por agentes privados (ANNUATI NETO, 2001). A idéia é que a exploração desse tipo de bem está associada a um caso de monopólio natural, onde a livre entrada de competidores dá origem a duplicações de investimentos elevados que acabam por onerar os consumidores ou desestruturar a oferta dos serviços.

Embora existam argumentos contrários à aplicabilidade desse entendimento à realidade da exploração da infraestrutura aeroportuária, ele ainda está presente nos fundamentos do atual arcabouço constitucional brasileiro. A Constituição Federal de 1988 prevê em seu art. 21 que 
essa exploração pode ocorrer de forma direta pela União ou mediante autorização, concessão ou permissão (BRASIL, 2010).

Associando a visão do aeroporto como local onde interagem os diversos atores do transporte aéreo à sua natureza de bem público, fica claro que seu desenvolvimento é objeto de interesse legitimo de diversas partes. Kawamoto (1994) ressalta o papel do transporte no desenvolvimento social e econômico e defende que o planejamento aeroportuário só terá sucesso se ele estiver integrado ao planejamento social e econômico da nação ou da região.

A necessidade de integrar o planejamento aeroportuário com as demandas da sociedade resta evidente quando se associam os eventos que demonstraram falhas no setor aéreo brasileiro na segunda metade dos anos 2000 ao descompasso entre o crescimento da demanda pelo transporte aéreo e a oferta de infraestrutura.

Sob uma perspectiva sistêmica, o aeroporto é o ponto onde há a interação dos diversos atores envolvidos com o setor: o operador do aeroporto, o operador aéreo, empresas de prestação de serviços auxiliares ao transporte aéreo, diversos órgãos públicos, clientes, etc. Conforme analisam Ashford et Al. (1997), a relação entre os envolvidos na operação de um aeroporto é complexa e nem sempre os interesses são convergentes.

A partir de avaliação do sistema de transporte aéreo nacional é possível listar os seguintes atores principais no que toca especificamente à exploração e planejamento da infraestrutura de aeroportos.

\begin{tabular}{|l|l|}
\hline \multicolumn{1}{|c|}{ Função no Sistema } & \multicolumn{1}{|c|}{ Principais Atores } \\
\hline $\begin{array}{l}\text { Exploração } \\
\text { infraestrutura }\end{array}$ & $\begin{array}{l}\text { INFRAERO; Comando da Aeronáutica - COMAER; Governos Estaduais; } \\
\text { Governos Municipais; Empresas privadas }\end{array}$ \\
\hline Regulação & $\begin{array}{l}\text { Agência Nacional de Aviação Civil - ANAC; Comando da Aeronáutica - } \\
\text { COMAER }\end{array}$ \\
\hline Planejamento & $\begin{array}{l}\text { Governo Federal; Conselho Nacional de Aviação Civil - CONAC; Secretaria de } \\
\text { Aviação Civil - SAC; Governo Estadual; Governo Municipal; INFRAERO; } \\
\text { Outros exploradores }\end{array}$ \\
\hline Fiscalização & ANAC; Tribunal de Contas da União - TCU \\
\hline Clientes & $\begin{array}{l}\text { Empresas de transporte aéreo; Proprietários de aeronaves; Passageiros; Emissor e } \\
\text { recebedor de carga/correios; Empresas de Serviços Auxiliares do Transporte } \\
\text { Aéreo - ESATA; Comerciantes; Usuário da infraestrutura e conveniência das } \\
\text { áreas públicas do aeroporto; Empresas de transporte de turistas; Acompanhantes } \\
\text { de passageiros }\end{array}$ \\
\hline $\begin{array}{l}\text { Outras } \\
\text { interessadas }\end{array}$ & \begin{tabular}{l} 
Associações de moradores do entorno; Construtores de aeronaves \\
\hline Parceiros
\end{tabular} \\
\hline
\end{tabular}

Quadro 1: Principais atores envolvidos do sistema de transporte aéreo 
A exploração da infraestrutura aeroportuária é atividade privativa da União, que pode realizála de forma direta ou mediante autorização, concessão ou permissão. Na prática, a exploração dos principais aeroportos do país cabe à Empresa Brasileira de Infraestrutura Aeroportuária INFRAERO, que processou cerca de 113 milhões de passageiros no ano de 2009 em seus 67 aeroportos, o que representa aproximadamente $97 \%$ do transporte aéreo nacional (INFRAERO, 2010). Constituída pela Lei Federal nº 5.862, de 1972, a INFRAERO é uma empresa pública dotada de personalidade jurídica de direito privado, patrimônio próprio, autonomia administrativa e financeira e está subordinada, desde março de 2011, à Secretaria de Aviação Civil da Presidência da República.

Outros agentes exploradores da infraestrutura aeroportuária são os Governos de Estado e as Prefeituras Municipais. Em alguns casos específicos, a efetiva exploração fica a cargo de empresas privadas, que mantém contrato com as entidades da federação. Em outros casos a exploração é responsabilidade do Comando da Aeronáutica, o que ocorre sobretudo em localidades de interesse estratégico.

A atividade de exploração de aeroportos apresenta-se bastante regulada e essa regulação abrange desde aspectos da concessão da exploração até padrões operacionais, passando por requisitos técnicos para projetos de novos aeroportos ou reforma de infraestrutura existente. No que toca ao planejamento aeroportuário, são entidades legítimas para regulação do setor a Agência Nacional de Aviação Civil - ANAC e o Departamento de Controle do Espaço Aéreo - DECEA do Comando da Aeronáutica, às quais cabem a definição dos requisitos técnicos, sendo de competência exclusiva da primeira a regulação de aspectos econômicos como outorga e definição de tarifas.

Quanto à definição de políticas e diretrizes para o planejamento da infraestrutura aeroportuária em nível nacional, tal prerrogativa cabe diretamente ao Governo Federal. Em última instância representado pela Presidência da República, o Governo Federal é assessorado pelo Conselho de Aviação Civil - CONAC quanto à formulação de políticas referentes à aviação civil e, como órgão executivo, conta com a Secretaria de Aviação Civil, ligada diretamente à Presidência da República e com status de Ministério, cuja finalidade precípua é a formulação, coordenação e supervisão das políticas para o desenvolvimento do setor de aviação civil e das infraestruturas aeroportuária e aeronáutica civil (BRASIL, 2011). 
Abreu (2008) comenta que o interesse dos governos estaduais e municipais no planejamento do sistema de transporte aéreo ocorre de forma pontual, visando ao crescimento e ao desenvolvimento da região que lhe compete gerenciar. Assim, a participação desses no planejamento aeroportuário ocorre essencialmente através de parcerias com a entidade pública ou empresa responsável pela administração dos aeródromos, podendo disponibilizar recursos para investimentos em suas regiões.

Sobre as entidades que exploram a infraestrutura, essencialmente suas atribuições estão relacionadas à confecção de projetos de ampliação ou novas construções e coordenação da execução desses. Com a publicação da Resolução ANAC nº 158, de julho de 2010 (ANAC, 2010), há uma maior autonomia para confecção do projeto por parte desses interessados, sendo resguardado ao poder público, representado neste caso pela Agência, a verificação da adequação do executado em relação aos requisitos de segurança existentes. Além da fiscalização da ANAC quanto à segurança, quando há a utilização de recursos públicos, o Tribunal de Contas da União (TCU) tem a atribuição de fiscalizar a aplicação correta e eficiente desses recursos.

Analisando o setor, constata-se a diversidade de clientes da infraestrutura aeroportuária. Tomando o conceito de aeroporto como todo aeródromo público dotado de instalações e de facilidades para apoio às operações de aeronaves e de embarque e de desembarque de pessoas e de cargas em geral (ANAC, 2008), considera-se que essas instalações e facilidades podem ser de interesse de diversos públicos e compreendidas dentro da seguinte classificação: operacional, apoio e acesso.

A infra-estrutura operacional são estruturas, instalações e facilidades destinadas diretamente à navegação e aos serviços aéreos. A infra-estrutura de apoio compreende o restante dos componentes físicos existentes no sítio que oferecem um tipo de serviço não diretamente relacionado à navegação aérea. Por fim, a infraestrutura de acesso compreende componentes referentes ao acesso viário ao aeródromo (ABREU, 2008).

Nesse contexto de múltiplos serviços, tem-se como clientes tradicionais do aeroporto: operadores de aeronaves, passageiros, pessoas emissoras e recebedoras de carga em geral, empresas de serviços auxiliares ao transporte aéreo e outros comerciantes que alugam áreas do aeroporto para realização de suas atividades. Numa visão mais ampla do aeroporto como 
infraestrutura pública, há de se considerar os acompanhantes dos passageiros, os próprios usuários da infraestrutura de apoio e conveniência das áreas públicas, empresas de transporte de turistas, entre outros públicos.

Para realização de seu serviço, a administração do aeroporto conta ainda com parceiros diversos, como o órgão de controle de tráfego e todo um conjunto de representações de entidades públicas necessárias ao funcionamento do aeroporto, como órgãos de polícia (federal, militar, civil), entidade de trânsito urbano, receita federal, vigilância sanitária, vigilância agropecuária, entre outras.

Concluindo a análise do sistema de transporte aéreo cabe ressaltar a existência de atores que não são participantes efetivos da realização diária do transporte aéreo. Os objetivos dos fabricantes de aeronaves devem ser conhecidos pelos planejadores da infraestrutura, posto que decisões sobre tamanho e configuração de aeronaves apresentam influência direta na infraestrutura no médio ou longo prazo. Por sua vez, apesar de não diretamente atuantes, os interesses da comunidade de entorno, por exemplo, devem ser considerados numa perspectiva ampla de planejamento.

Em síntese, o planejamento aeroportuário é um objeto de políticas públicas e de interesse estratégico para o desenvolvimento de uma região. A elaboração de políticas públicas, conforme Cristo (2002), pressupõe uma análise histórica que possibilite quantificar e compreender a lógica dos diversos processos que interagem com os sistemas objetos dessas políticas. No entanto, o conhecimento do passado, o diagnóstico do presente e o desenho minucioso desses sistemas não são suficientes para a elaboração de políticas públicas que condicionem e orientem o futuro.

\section{Prospectiva estratégica}

A clássica definição de planejamento proposta por Ackoff (1973) é a concepção de um futuro desejado, bem como os meios reais para chegar neste futuro. Sucintamente o processo de planejamento pode ser entendido como um esforço orientado para avaliação de um dado contexto a fim de obter subsídios para tomada de decisões e estabelecimento de diretrizes e ações para consecução de objetivos. Essas diretrizes e ações não são inflexíveis e ao longo do 
tempo é frequente a necessidade de ajustes, seja quanto às ações ou recursos definidos, seja quanto aos próprios objetivos.

O paradigma tradicional do planejamento e seus elementos constituintes, como a previsão perfeita, a matematização dos fenômenos sociais, a busca pelo ótimo, a menor relevância dada aos demais atores sociais e o ato de planejar como ação unidirecional neutra daquele que planeja (PERESTRELO, 1999), reflete uma visão limitada da complexidade social e dos resultados do planejamento sobre essa realidade.

Essa complexidade está associada às incertezas relacionadas com todos os fatores que compõem o ambiente social, incluindo os comportamentos dos atores da sociedade. Essas incertezas demandam um processo de reflexão estratégico igualmente mais complexo que o simples ato de estabelecer ações para se chegar a objetivos. Ainda mais, o exercício de reflexão deve ser capaz de antecipar elementos de cenários futuros a fim de preparar a organização para atuar com eficácia dentro dessas realidades possíveis.

Independente da abordagem assumida, todo planejamento envolve a necessidade de prever eventos futuros ou antecipar a visualização de cenários futuros. Assim, a prospectiva está estritamente vinculada ao exercício de planejamento.

Prospectiva pode ser entendida como a capacidade de olhar para o futuro e utilizar as introspecções de maneira útil, para moldar estratégias ou definir novos mercados, produtos e serviços. Compreende um processo que busca a identificação de tendências na ciência, na tecnologia, na economia, na política e na sociedade e envolve o uso de métodos e técnicas para reunir, avaliar e interpretar informação relevante para apoiar a tomada de decisões (SLAUGHTER, 1998 apud YAÑEZ, 2010).

O termo foresighting é utilizado em língua inglesa com a mesma conotação de prospectiva. Segundo Hamel e Prahalad (1995) o entendimento sobre foresight deve refletir o pensamento de que a previsão do futuro precisa ser fundamentada em uma percepção detalhada das tendências dos estilos de vida, da tecnologia, da demografia e geopolítica, mas que se baseia igualmente na imaginação e no prognóstico.

A prospectiva se mostra capaz de auxiliar organizações de variados tipos, podendo ser utilizada com objetivos exploratórios, aplicando-se à análise de questões macro e buscando 
projetar os futuros possíveis de um dado sistema. Além disso, pode servir como elemento numa cadeia de aprendizagem que venha possibilitar às organizações antecipar a evolução do presente e, com base em simulações, testar estratégias existentes e/ou definir uma nova visão estratégica condutora de ação (PERESTRELO, 1999). A prospectiva é, portanto, freqüentemente estratégica, senão pelas suas conseqüências, ao menos por suas intenções (GODET, 2000).

Rohrbeck et al. (2007) destaca quatro campos principais para aplicação da prospectiva estratégica (Figura 1).

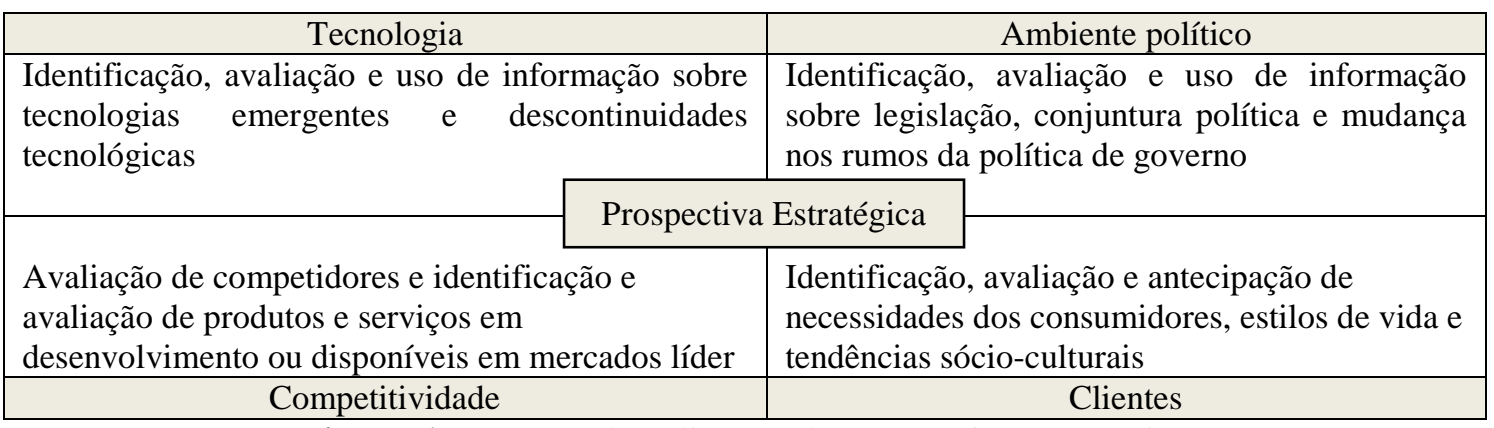

Figura 1: Campos de aplicação da prospectiva estratégica

Pode-se supor que um processo de planejamento orientado exclusivamente pelos interesses da organização que planeja fica comprometido quanto à sua capacidade de ler a dimensão político-social, por não considerar explicitamente as estratégias e objetivos dos demais atores. Como conseqüência essa ação unidirecional tende a gerar uma visão limitada do futuro e, portanto, decisões não eficientes no médio e longo prazo.

Essa visão é corroborada por Godet (2000), para o qual não é razoável considerar a atividade de planejamento como um processo restrito ao ambiente dos decisores e dos executantes, devendo ser considerado o conjunto dos atores, ativos e passivos, implicados.

Justificando a necessidade de atentar para a importância da relação de uma organização com seus diferentes stakeholders, Donaldson e Preston (1995) defendem que esses têm interesses legítimos nos resultados da atividade da organização. Conforme Stoner e Freeman (1995) stakeholders "são os indivíduos ou grupos que são direta ou indiretamente afetados pela perseguição aos seus objetivos por parte de uma organização". Portanto, seus interesses 
devem ser considerados a partir de si mesmos e não como um veículo para atender aos interesses de outros agentes, sobretudo acionistas, no caso de organização privada, ou governo, na gestão pública.

Reconhecidos os benefícios de se considerar todos os atores envolvidos no ambiente de planejamento, cabe voltar a atenção para a prática do trabalho de prospectiva. Verificam-se diversas técnicas e ferramentas analíticas e/ou metodológicas que podem abranger partes do processo ou até mesmo sua totalidade, compreendendo as etapas iniciais de identificação das diferentes variáveis que irão alimentá-lo até a projeção de cenários possíveis.

Conforme Batista et al. (2008), algumas técnicas são mais adequadas às finalidades exploratórias, como o método Delphi. Outras tem caráter mais analítico, como análise de tendências ou análise de impactos cruzados, enquanto outras tem caráter interpretativo, como a dinâmica de sistemas. Marcial e Costa (2001) apresentam referências à realização de diversos trabalhos prospectivos desde a década de 1970 e afirmam ser a prática ainda pouco divulgada no país.

Posto que o foco deste trabalho está no reconhecimento da importância de considerar os diversos atores que estão envolvidos ou são impactados pelos resultados do planejamento aeroportuário, cabe ressaltar a análise da estratégia de atores ou análise do jogo de atores. Como explicam Perestrelo e Caldas (2000), essa análise é uma das etapas da metodologia prospectiva de elaboração de cenários, porém pode ser utilizada isoladamente, sendo de utilidade para compreensão da relação entre os atores. O objetivo principal é a identificação dos desafios estratégicos e objetivos associados aos atores, assim como de suas estratégias, capacidade de influência, fragilidades, possíveis alianças e conflitos.

Os objetivos específicos da análise da estratégia de atores são: (i) identificar e caracterizar os diferentes atores-chave; (ii) perceber conflitos ou alianças possíveis entre os atores, e de que modo podem orientar a evolução do sistema; (iii) contribuir para uma maior participação/implicação e reflexão por parte dos atores; (iv) confrontar os objetivos de cada ator em presença dos outros e avaliar as relações de força existentes; (v) $\square$ elaborar recomendações estratégicas (PERESTRELO e CALDAS, 2000). 
Para execução da análise a literatura referencia o método MACTOR (Matriz de Alianças e Conflitos: Táticas, Objetivos e Recomendações). Inspirada na teoria dos jogos e na análise sociológica das organizações, essa ferramenta busca auxiliar na identificação sistemática e objetiva das estratégias dos diferentes atores e auxilia no reconhecimento das divergências e convergências entre esses. Adicionalmente traz critérios que possibilitam o agrupamento dos atores com base em seus objetivos e uma análise desses objetivos considerando o grau de mobilização e o grau de conflitualidade entre eles (GODET, 2000; PERESTRELO e CALDAS, 2000; BATISTA et al., 2008).

Tem-se registros de aplicações bem sucedidas do MACTOR, incluindo seu uso em estudos prospectivos relacionados a infraestrutura aeroportuária para a região de Paris, na França. Esses estudos considerando a realidade de Paris são tomados como exemplo por Godet (2000; 2006) para demonstração do método e ilustração de outros resultados decorrentes da aplicação da prospectiva estratégica.

A figura 2 apresenta o encadeamento das sete etapas que compreender o MACTOR e, em particular, oferece uma visão do fluxo do desenvolvimento das diversas matrizes resultantes das etapas.

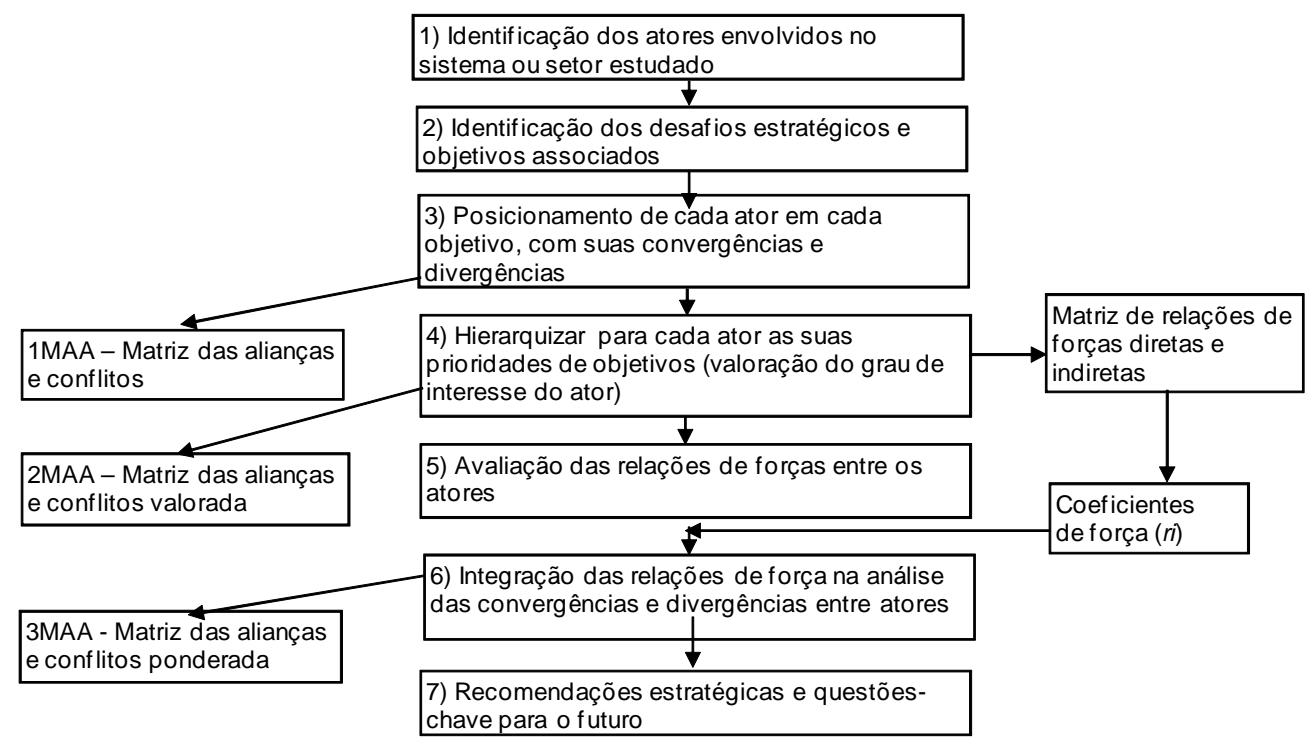

Figura 2 - Ilustração das etapas do MACTOR 
Por escapar ao objetivo deste artigo detalhar a descrição do método, para uma melhor compreensão sobre sua estruturação ou considerações sobre vantagens de sua aplicação e mesmo limitações, recomenda-se a leitura dos trabalhos de Godet $(2000,2006)$ e dos estudos de Batista et al. (2006, 2008), esses últimos aplicados na realidade brasileira e que enfocaram o setor energético.

De forma geral, a avaliação dos resultados desses trabalhos nacionais aponta que a análise da estratégia de atores suportada pelo MACTOR demonstra-se efetivamente útil para abordar o problema da complexidade do processo de planejamento em ambientes onde existem muitos stakeholders, o que se configura exatamente o caso do planejamento da infraestrutura aeroportuária.

\section{Conclusões}

A diversidade dos enfoques pelos quais se aborda o planejamento aeroportuário permite contribuições oriundas de diversas áreas do conhecimento. Neste artigo, o tema foi tomado enquanto problema de política pública e inserido na perspectiva das relações de poder entre agentes envolvidos com o processo de planejamento.

Quando se fala em política pública, a atenção aos interesses das diversas esferas da sociedade se apresenta como um requisito imprescindível para a eficácia de qualquer ação governamental. Posto que a infraestrutura aeroportuária é tratada no país como um bem público, o desafio de explorar eficientemente essa infraestrutura, seja de forma direta ou indireta, e, mais ainda, planejar seu desenvolvimento de forma a suprir as necessidades de todos os públicos interessados, cabe ao Estado.

Na esfera institucional, a criação da Secretaria de Aviação Civil ocorre dentro de um contexto de crescente demanda por transporte aéreo, resultante do próprio desenvolvimento que o setor vem apresentado, somado à perspectiva da realização de dois grandes eventos esportivos a serem sediados pelo país em meados da década de 2010.

Nesse cenário, a introdução do novo órgão, subordinado diretamente à Presidência da República, pode representar importante passo no sentido de estabelecer de um novo modelo institucional para a gestão da aviação civil no Brasil. Verifica-se ter sido conferida a 
Secretaria a importante e crítica atribuição de promover a harmonização dos planejamentos relativos à aviação civil, à infraestrutura aeroportuária civil e à infraestrutura de navegação aérea civil no âmbito da União, dos Estados e dos Municípios.

No contexto do planejamento aeroportuário, dada a diversidade de serviços que são oferecidos pelo aeroporto contemporâneo e os diferentes tipos de clientes e outras partes interessadas, é evidente que o processo de planejar a prestação do serviço está carregado de complexidade. Vislumbrando a tendência de uso das áreas públicas de um aeroporto como elemento de infraestrutura pública, identificar os objetivos, interesses e estratégias de ação dos diversos públicos com os quais há interação torna-se fudamental para um resultado eficaz e eficiente do processo de planejamento.

Considerando que as práticas tradicionais de planejamento demonstram-se insuficientes para contextos complexos, a prospectiva estratégica com suas referências conceituais, técnicas e métodos associados apresenta utilidade como suporte ao necessário processo de avaliação dos impactos sociais, econômicos e ambientais do processo de planejamento em transportes, especificamente o planejamento aeroportuário.

A atividade prospectiva envolve diversos elementos da realidade social. Especialmente em setores altamente regulados, como é o caso do transporte aéreo, o ambiente político torna-se elemento crucial. Sendo que na realidade brasileira o próprio governo é o formulador e grande executor das políticas públicas para o desenvolvimento da infraestrutura aeroportuária, o esforço no sentido de prospectar este campo parece ser compensador.

$\mathrm{O}$ atendimento das expectativas e objetivos dos diversos atores do setor, contudo, requer uma capacidade cognitiva adicional por parte de quem planeja e esforço para analisar o jogo destes atores, buscando identificar os objetivos e interesses de cada ator, as convergências e divergências em relação aos objetivos de outros, sua capacidade de influenciar e suas fraquezas. Por fim, todo esse esforço tem que resultar em subsídios para visualizar as questões-chave para uma solução eficiente para o planejamento aeroportuário.

Conforme visto, o campo da prospectiva estratégica oferta propostas de soluções para essa análise do jogo dos atores, ou análise da estratégia de atores, cujo objetivo principal é exatamente a identificação dos objetivos de cada envolvido, assim como suas estratégias, 
capacidade de influência, fragilidades, possíveis alianças e conflitos. Neste trabalho destacouse o método MACTOR como ferramenta indicada pela literatura e já utilizada inclusive no ambiente do planejamento da infraestrutura aeroportuária, conforme documentado por Godet (2000, 2006).

Especificamente quanto ao MACTOR, defende-se que seu uso pode trazer benefícios relevantes para o planejamento aeroportuário no caso brasileiro. A inclusão dos interesses dos diferentes atores sociais na análise prospectiva, sobretudo daqueles que tem interesse no resultado do planejamento pode possibilitar a identificação de oportunidades para o estabelecimento de ações mais eficazes e eficientes.

O planejamento do desenvolvimento de um aeroporto representa um grande desafio pelo jogo de interesses que se forma e os resultados da aplicação desse método podem ser úteis para a execução da tarefa. É de se supor, contudo, que a aplicação do método como instrumento de política pública requeira um esforço integrado de planejamento que envolveria diversas esferas do poder público e da sociedade civil.

Em síntese, como importante elemento da infraestrutura de uma região, ocupando extensa área e processando atividades que impactam diversas partes da sociedade, as decisões sobre o desenvolvimento de um aeroporto são interesse legítimo de vários atores. Mais do que isso, as próprias ações desses atores acarretam impacto sobre a eficácia do planejamento da infraestrutura. Esse ambiente de intensa interação e de interesses e objetivos diversos se apresenta terreno propício para utilização da perspectiva ampla e sensível às forças dos atores que fundamenta a prospectiva estratégica. 


\section{Referências}

Abreu, F. E. L. V. (2008). Análise Sistêmica do Setor Aéreo Brasileiro: Propostas para o Planejamento do Setor. Dissertação de Mestrado, Publicação T.DM-005A/2008, Departamento de Engenharia Civil e Ambiental,Universidade de Brasília, Brasília, DF 156p.

Ackoff, R. (1970) A Concept of Corporate Planning. John Wiley \& Sons. New York, NY.

ANAC. (2008) Regulamentos Brasileiros de Aviação Civil nº 01: Definições, Regras de Redação e Unidades de Medida. Agência Nacional de Aviação Civil, Brasília, Disponível em: http://www.anac.gov.br/ biblioteca/rbha.asp. Acesso em: jul/2010.

ANAC. (2010) Resolução $n^{\circ}$ 158: Dispõe sobre a Autorização Prévia para a Construção de Aeródromos e seu Cadastramento junto à ANAC. Agência Nacional de Aviação Civil, Brasília, Disponível em: http://www.anac.gov.br/ biblioteca/resolucoes.asp. Acesso em: jul/2010.

Annuati neto, F. (2001) Regulamentação dos Mercados. In: Manual de Economia. 3.ed., Saraiva, São Paulo.

Batista, P. C. S.; Linhares, G. C.; Melo, R. S.; Klein, M. C. A.; Almeida, F. E. B. A. (2006) O Poder dos Atores e a Gestão da Estratégia Política no Setor Energético: uma Reflexão à Luz da Teoria dos Stakeholders e da Análise Prospectiva. Anais do X Colóquio Internacional sobre Poder Local: Salvador.

Batista, P. C. S.; Linhares, G. C.; Klein, M. C. A.; Almeida, F. E. B. A. (2008) Oportunidades à Formulação de Estratégicas Cooperativas: uma Aplicação da Metodologia de Análise da Estratégia de Atores no Setor de Energia Elétrica. Anais do XXXII Encontro da Associação Nacional de Pós-Graduação e Pesquisa em Administração, ENANPAD: Rio de Janeiro.

BRASIL. (1988) Constituição da República Federativa do Brasil. 22ª ed. República Federativa do Brasil, Senado Federal, Centro de Documentação e Informação - Coordenação de Publicações. Brasília.

Coates, J. (1985) Foresight in Federal Government Policy Making. Futures Research Quartely, v. 1, p.29-53.

Cristo, C. M. P. N. (2002) Prospectiva Estratégica: Instrumento para a Construção do Futuro e para a Elaboração de Políticas Públicas. Anais do VII Congreso Internacional del CLAD sobre la Reforma del Estado y de la Administración Pública, CLAD: Lisboa. Disponível em: http://unpan1.un.org/intradoc/groups/public/documents/CLAD/clad0043707.pdf., Acesso em: ago/2010.

Donaldson, Thomas; Preston, Lee E. (1995) The stakeholder theory of the corporation: concepts, evidence and implications. Academy of management review. Vol 20, n1, pp 65-91, 1995.

DPP. (1997) Prospectiva e cenários: uma breve introdução metodológica. Departamento de Prospectiva e Planejamento, Lisboa.

Godet, M. (2000) A caixa de ferramentas da prospectiva estratégica: problemas e métodos. Caderno do Centro de Estudos de Prospectiva e Estratégia, nº 5, Lisboa.

Godet, M. (2006) Creating Futures: Scenario Planning as a Strategic Management Tool. Economica Ltd. Paris.

Guimarães, E. A. (2003) Aspectos Regulatórios do Mercado de Transporte Aéreo no Brasil. In: Guimarães, E. A. Salgado, L. H. (2003), Notas Técnicas nº. 23: A Regulação do Mercado de Aviação Civil no Brasil. Instituto de Pesquisa Econômica Aplicada - IPEA. Brasília. 
Hamel, G., Prahalad, C. K. (1995) Competindo pelo futuro: estratégias inovadoras para obter o controle do seu setor e criar os mercados de amanhã. Campus. Rio de Janeiro.

INFRAERO. (2010) A INFRAERO e o Desafio do Novo Brasil. Empresa Brasileira de Infraestrutura Aeroportuária, Ministério da Defesa, Brasília. Disponível em: http://www.infraero.gov.br/item_gera.php?gi=instempr\&menuid=inst\&PHPSESSID=0vpb30kn 8e9clm26mau2s18s00. Acesso em: ago/2010.

Jesus jr, L. B. de; Ferreira jr, H. M. (2010) Análise da concorrência no setor de aviação civil brasileiro. Anais XIII Encontro Regional de Economia, ANPEC: Porto Alegre. Disponível em: http://www.ppge.ufrgs.br/anpecsul2010/artigos/26.pdf. Acesso em: ago/2010.

Kawamoto, Eiji (1994) Análise dos Sistemas de Transporte. 2.Ed. São Carlos: Universidade de São Carlos, São Paulo.

Marcial, E. C., Costa, A. J. L. (2001) O Uso de Cenários Prospectivos na Estratégia Empresarial: Vidência Especulativa ou Inteligência Competitiva? Anais do XXV Encontro da Associação Nacional de Pesquisa em Administração, ENANPAD: Campinas.

Palhares, G. L., Espírito Santo jr., R. A. (2001) O Turismo e o Transporte Aéreo como Multiplicadores Socioeconômicos. In: Setti, J. R. A., Lima Jr., L. F. (eds.), Panorama Nacional da Pesquisa em Transportes 2001. Anais do XV Congresso da Associação Nacional de Pesquisa e Ensino em Transportes, ANPET, vol 2, pp. 225-232: Campinas.

Perestrelo, M. (1999) Prospectiva: planeamento estratégico e avaliação. Anais do I Congresso em Portugal sobre planeamento e avaliação de impactos sociais: Grândola. Disponível em: http://www.aps.pt/cms/docs_prv/docs/DPR462e0a77b4aca_1.PDF. Acesso em: jul/2010.

Perestrelo, M.; Caldas, J. M. C. (2000) Instrumentos de Análise para o Método dos Cenários: Estratégia de Actores. DINÂMIA, Dinâmia Working Paper, 2000/17: Lisboa. Disponível em: https://repositorio-iul.iscte.pt/bitstream/10071/476/1/wp17-2000.pdf. Acesso em: jul/2010.

Rohrbeck, R., et al. (2007) Strategic Foresight - a Case Study on The Deutsche Telekom Laboratories. Anais da International Society for Professional Innovation Management Conference, ISPIM: New Delhi. Disponível em: http://www.slideshare.net/Jack78/strategic-foresight-a-case-studyon-the-deutsche-telekom. Acesso em: ago/2010.

Salgado, L. H. (2009) Caos Aéreo e Tragédia dos Comuns: Falhas de Mercado e de Governo. In: Estado de uma nação: textos de apoio/Texto para discussão n. 1388. Instituto de Pesquisa Econômica Aplicada: Brasília.

Stoner, J. A. F.; Freeman, R. E. (1995) Administração. Rio de Janeiro: Prentice do Brasil.

Yañez, A. P. M. (2010) Prospectiva Estratégica no Sector Energético: Caso de Estudo da EDP. Dissertação de Mestrado. Faculdade de Ciências e Tecnologia/Universidade Nova de Lisboa: Lisboa. 